Historic, Archive Document

Do not assume content reflects current scientific knowledge, policies, or practices. 

United States Department of Agriculture

Animal and Plant Health Inspection Service

Program Aid Number 1685
The Horse Protection Act Understanding the Scar Rule

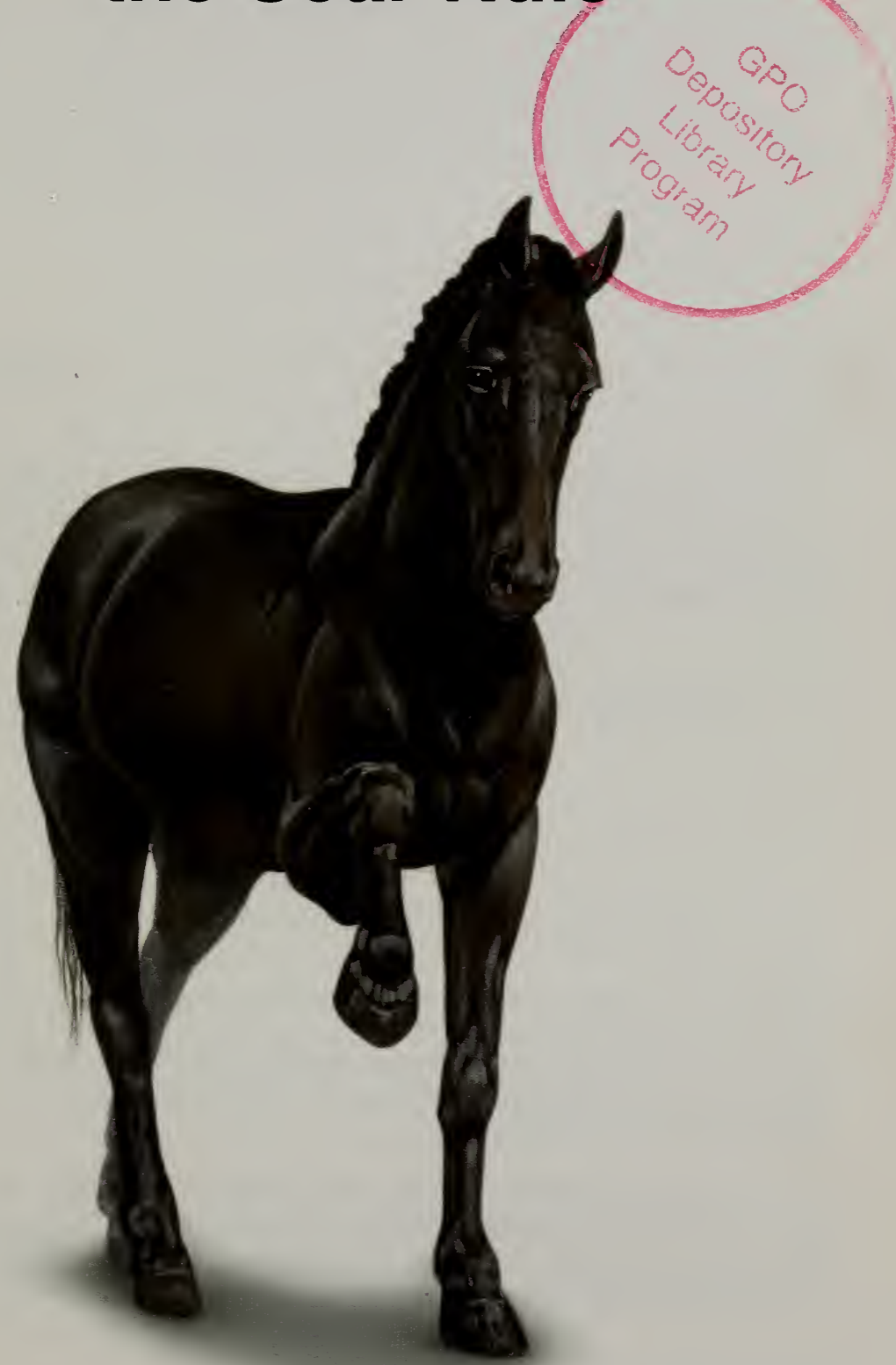


The U.S. Department of Agriculture (USDA) prohibits discrimination in all its programs and activities on the basis of race, color, national origin, sex, religion, age, disability, political beliefs, sexual orientation, or marital or family status. (Not all prohibited bases apply to all programs.) Persons with disabilities who require alternative means for communication of program information (Braille, large print, audiotape, etc.) should contact USDA's TARGET Center at (202) 720-2600 (voice and TDD).

To file a complaint of discrimination, write USDA, Director, Office of Civil Rights, Room 326-W, Whitten Building, 1400 Independence Avenue, SW, Washington, DC 20250-9410 or call (202) 720-5964 (voice and TDD). USDA is an equal opportunity provider and employer.

Issued February 2001

Photo credits: Photos in the brochure come from Animal Care's photo library. Where possible, we have credited individual APHIS photographers. 
Soring is the practice of inflicting pain on the limbs of a horse for the purpose of accentuating its gait. Trainers often achieve the high-stepping gait desirable in some breeds of show horses through patient and persistent training methods. Soring is a cruel shortcut some unscrupulous trainers use to achieve that same high-stepping gait. This practice is abusive to the horse and unfair to ethical trainers.

\section{The Scar Rule}

The HPA regulations are a set of rules written by USDA to support enforcement of the Act. The scar rule is one of these regulations. Any horse at a show, exhibition, sale, or auction found to be not in compliance with the scar rule is considered to be "sore" and shown in violation of the HPA.

The scar rule as found in Title 9 of the Code of Federal Regulations Section 11.3 reads:

The scar rule applies to all horses born on or after October 1, 1975. Horses subject to this rule that do not meet the following scar rule criteria shall be considered to be "sore" and are subject to all prohibitions of section 5 of the Act. The scar rule criteria are as follows:

(a) The anterior and anterior-lateral surfaces of the fore pasterns (extensor surface) must be free of bilateral granulomas $^{1}$, other bilateral pathological evidence of inflammation, and, other bilateral evidence of abuse indicative of soring including, but not limited to, excessive loss of hair.

(b) The posterior surfaces of the pasterns (flexor surface), including the sulcus or "pocket" may show bilateral areas of uniformly thickened epithelial tissue if such areas are free of proliferating granuloma tissue, irritation, moisture, edema, or other evidence of inflammation.

${ }^{1}$ Granuloma is defined as any one of a rather large group of fairly distinctive focal lesions that are formed as a result of inflammatory reactions caused by biological, chemical, or physical agents. 
This publication is not intended to be an all-inclusive list of the various conditions that constitute violations of the scar rule. Abnormalities occurring on the pasterns of horses can be many and varied, and the photographs and descriptions in this brochure do not illustrate all possible conditions.

The captions accompanying the photographs and other descriptions explain whether the condition illustrated is or is not allowed under the scar rule. You can use the following criteria and make comparisons to the additional photographs as aids to determining whether or not a horse's condition is in compliance. It is important to remember that, for a horse to be in violation of the scar rule, the scars indicative of soring must appear on both front pasterns of a horse. These scars do not need to be symmetrical, similar in appearance, or of the same type to constitute a scar rule violation.

\section{How To Determine Compliance}

There are three general criteria for determining whether a horse is in compliance with the scar rule:

\section{Do the scars appear on both front legs (i.e., bilaterally)?}

Scars indicative of soring must be bilateral to constitute a violation.

\section{Where are the scars located?}

For a horse to be in compliance with the scar rule, the anterior surfaces (front and sides) of its pasterns must be entirely free of scars indicative of soring. The posterior (back) surfaces of the pasterns must also be free of scars but are allowed to show uniformly thickened skin. Because of the difference between what is allowed on the front and back of the pastern, it is important to know where the boundaries of the anterior and posterior surfaces are located. There are three ways to determine these boundaries:

- Flattened-hand method. This is the simplest method to use. Start by flattening your hand, fingers together, and place your palm firmly against the back of the pastern. Any part of the pastern covered by your hand is part of the posterior surface; therefore, any scarring or uniformly thickened skin not covered by your hand indicates a violation of the scar rule (fig. 1). 


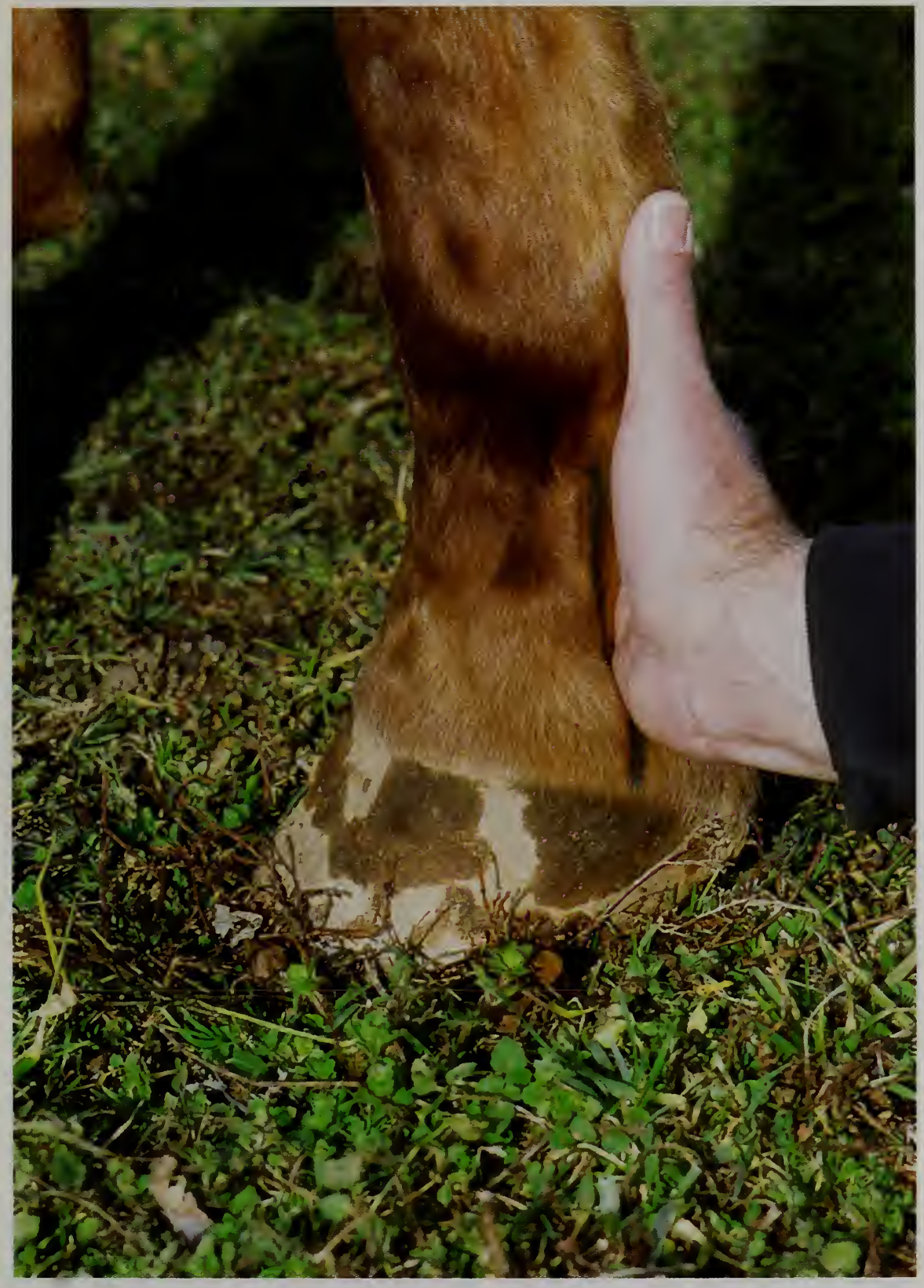

Figure 1-The flattened-hand screening method is one way to determine if a scar is on an anterior or posterior surface of a horse's pastern. (APHIS photo by Richard Watkins.) 
- Neurovascular bundle (NVB) method. The NVB is a group of veins, arteries, and nerves that run down the sides of the pastern. It can be located by finding the back surface of the pastern bone and then placing the upper surface of the nail of your index finger against the back surface of the bone. The fleshy part of the index finger is now covering the NVB. Any scarring or uniformly thickened skin covered by or extending forward from the finger indicates a violation of the scar rule (fig. 2).

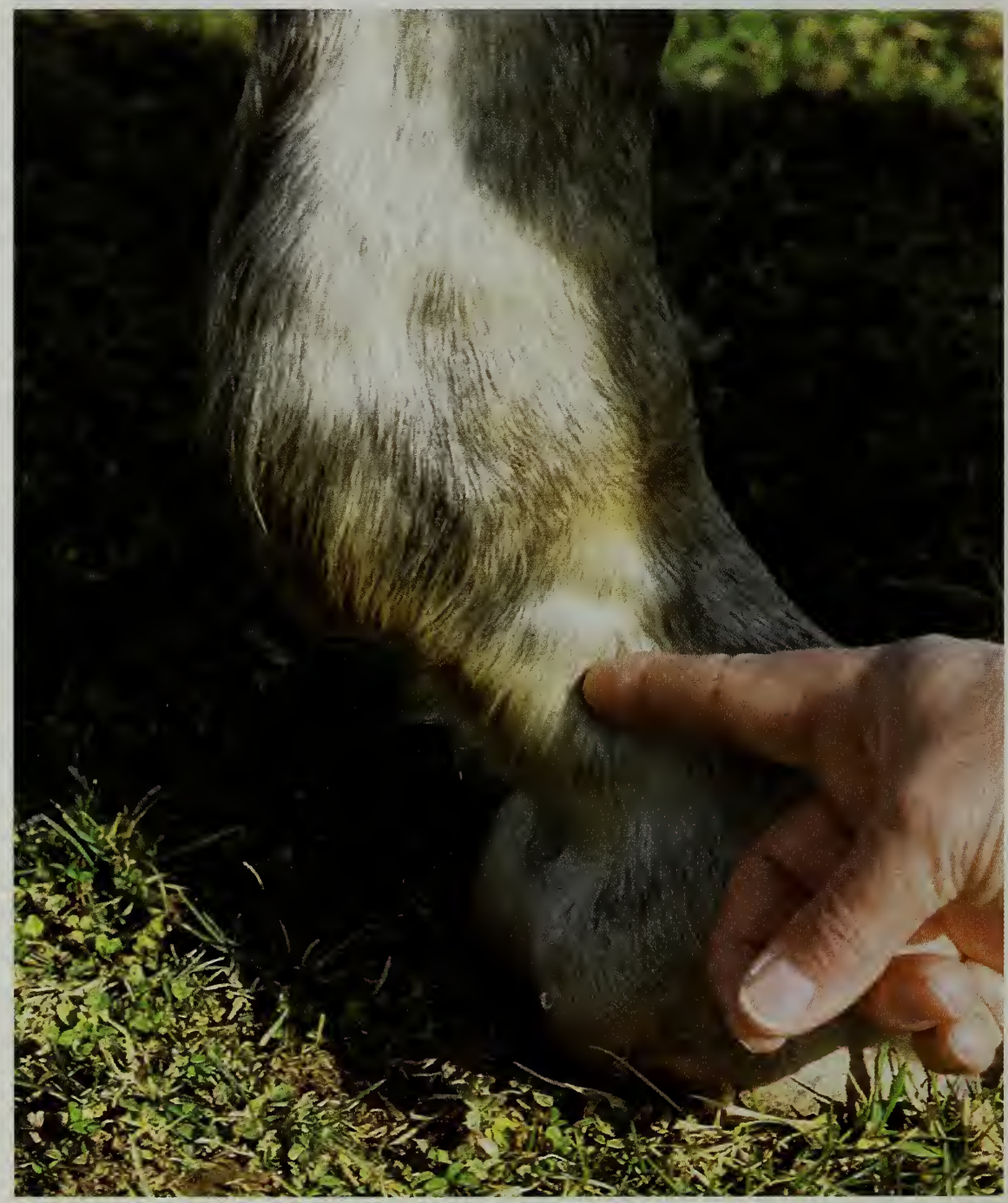

Figure 2-Another method uses the neurovascular bundle (NVB) to determine if a scar is in an unacceptable location on the pastern. (APHIS photo by Richard Watkins.) 
- Circumferential measurement. This method is used as the deciding method if the other two do not provide an absolute answer. The circumferential measurement requires the use of a measuring tape and a chart to analyze the results (fig. 3). It is a more complicated procedure. If you are interested in knowing more about this procedure, please contact USDAAPHIS Animal Care or a Horse Industry Organization (HIO) for further information.

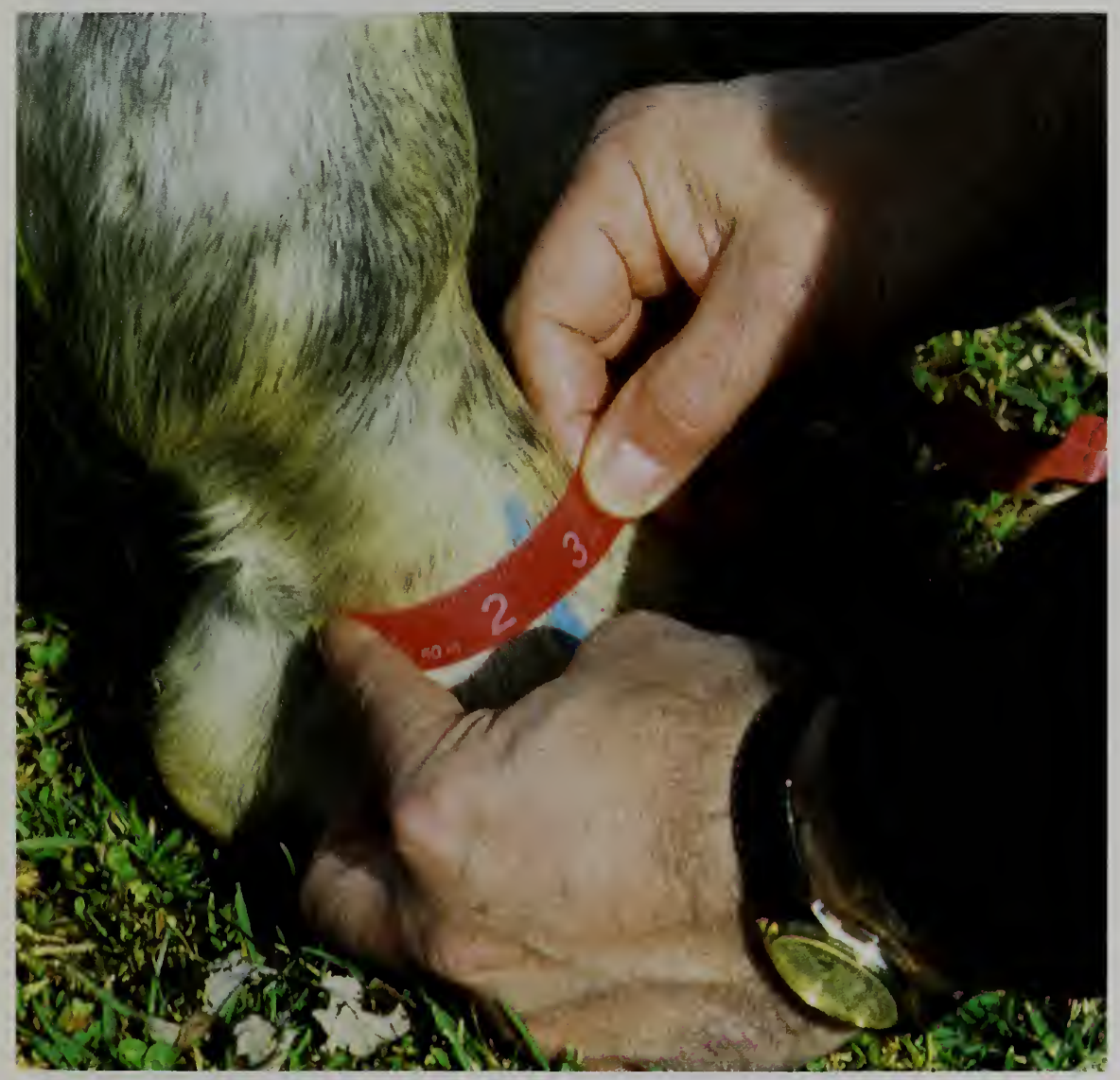

Figure 3-When the flattened-hand or NVB method is not sufficient to make a determination, circumferential measurements may be used. (APHIS photo by Richard Watkins.) 


\section{What do scars indicative of soring look like?}

The term "scar" used in this publication refers to several skin abnormalities described in the regulation. These must be indicative of soring to be a violation. Scarring or other abnormalities of the skin that result from injury or naturally occurring disease processes are not violations of the scar rule.

Figures 4-15 show examples of pasterns and skin abnormalities with captions that explain if they are allowed under the scar rule. 


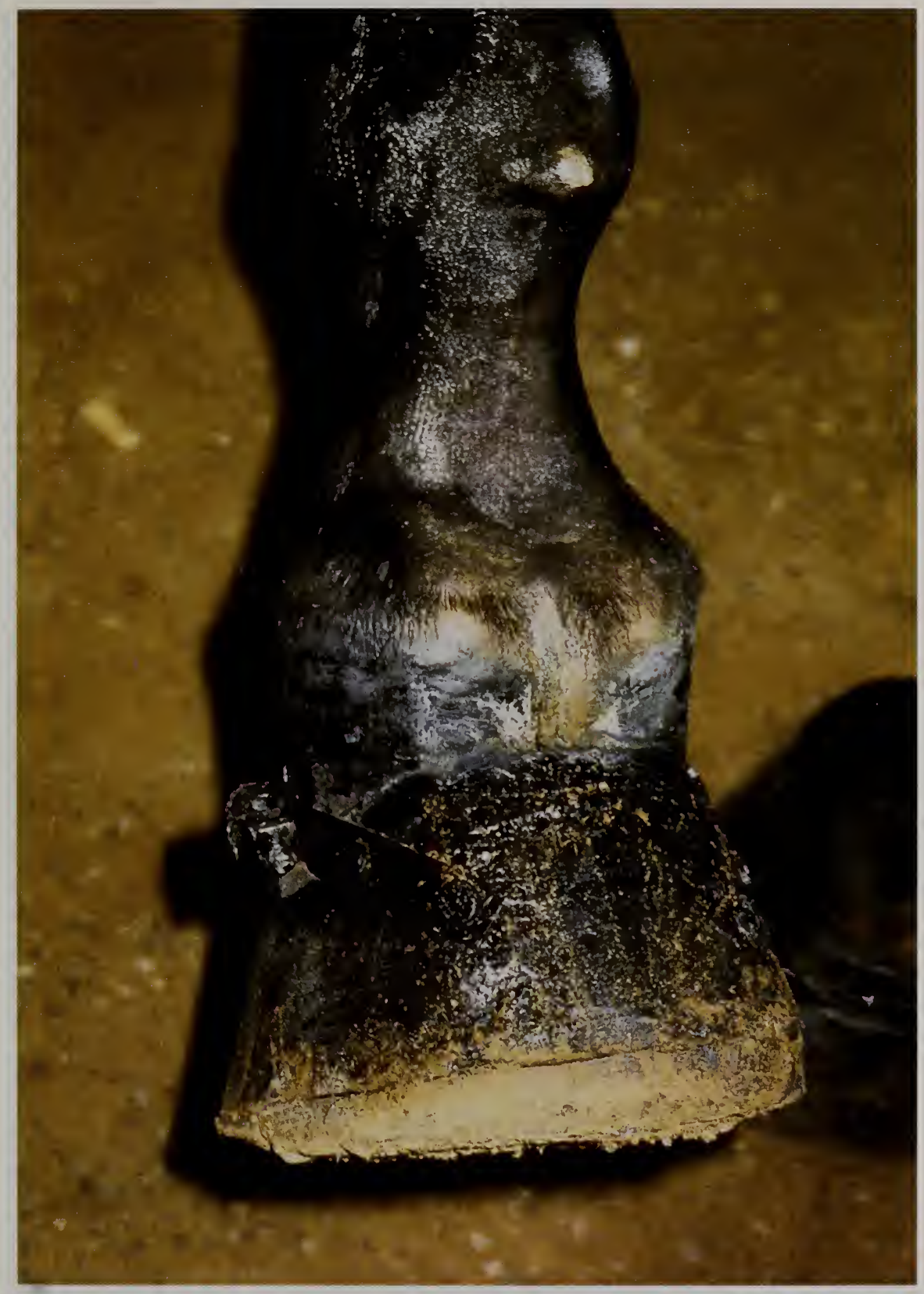

Figure 4-No violation. This is a normal pastern. There is no scarring present. 


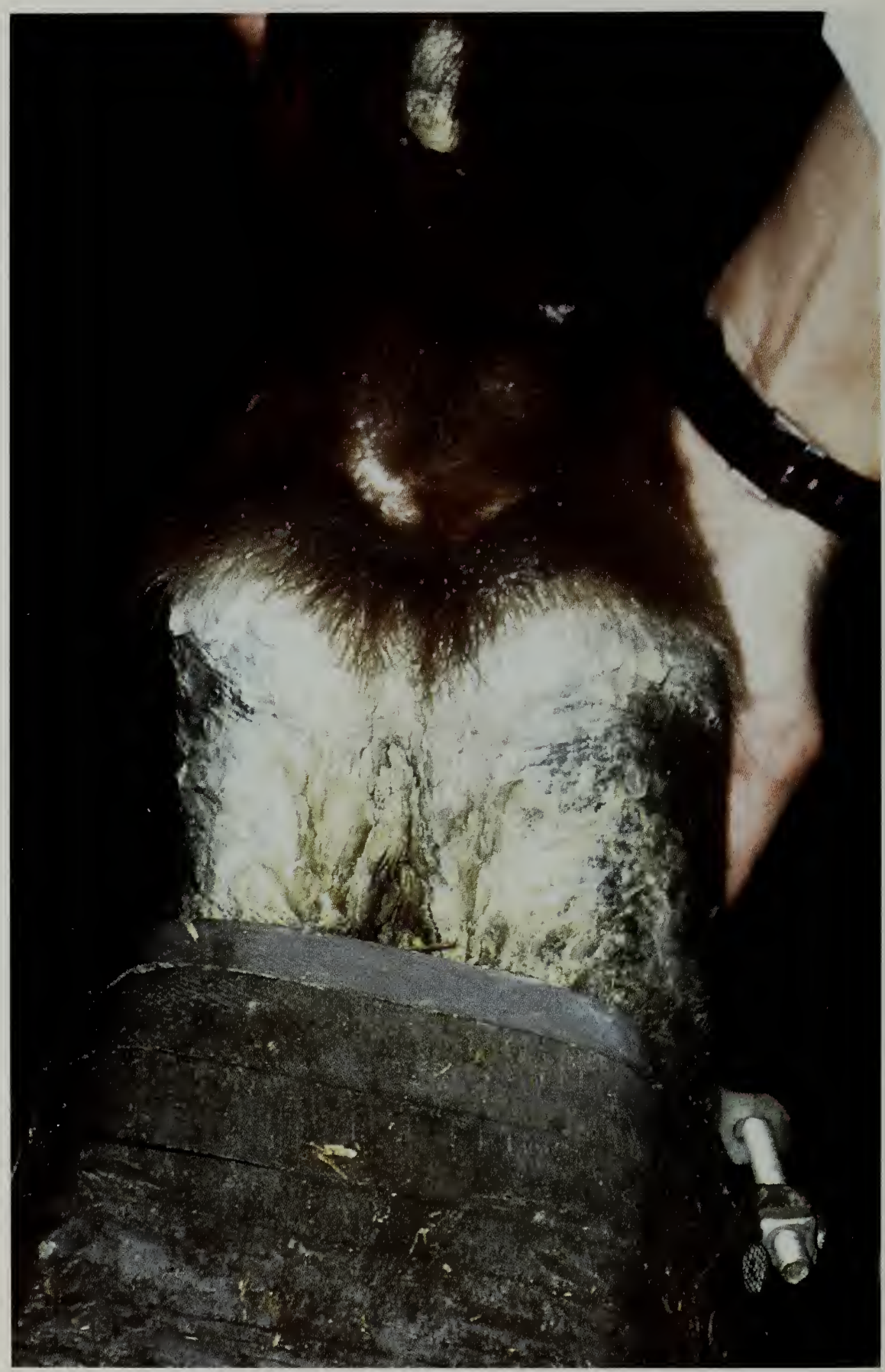

Figure 5-No violation. Only mild hair loss is apparent on the posterior (back) surface of the pastern. 


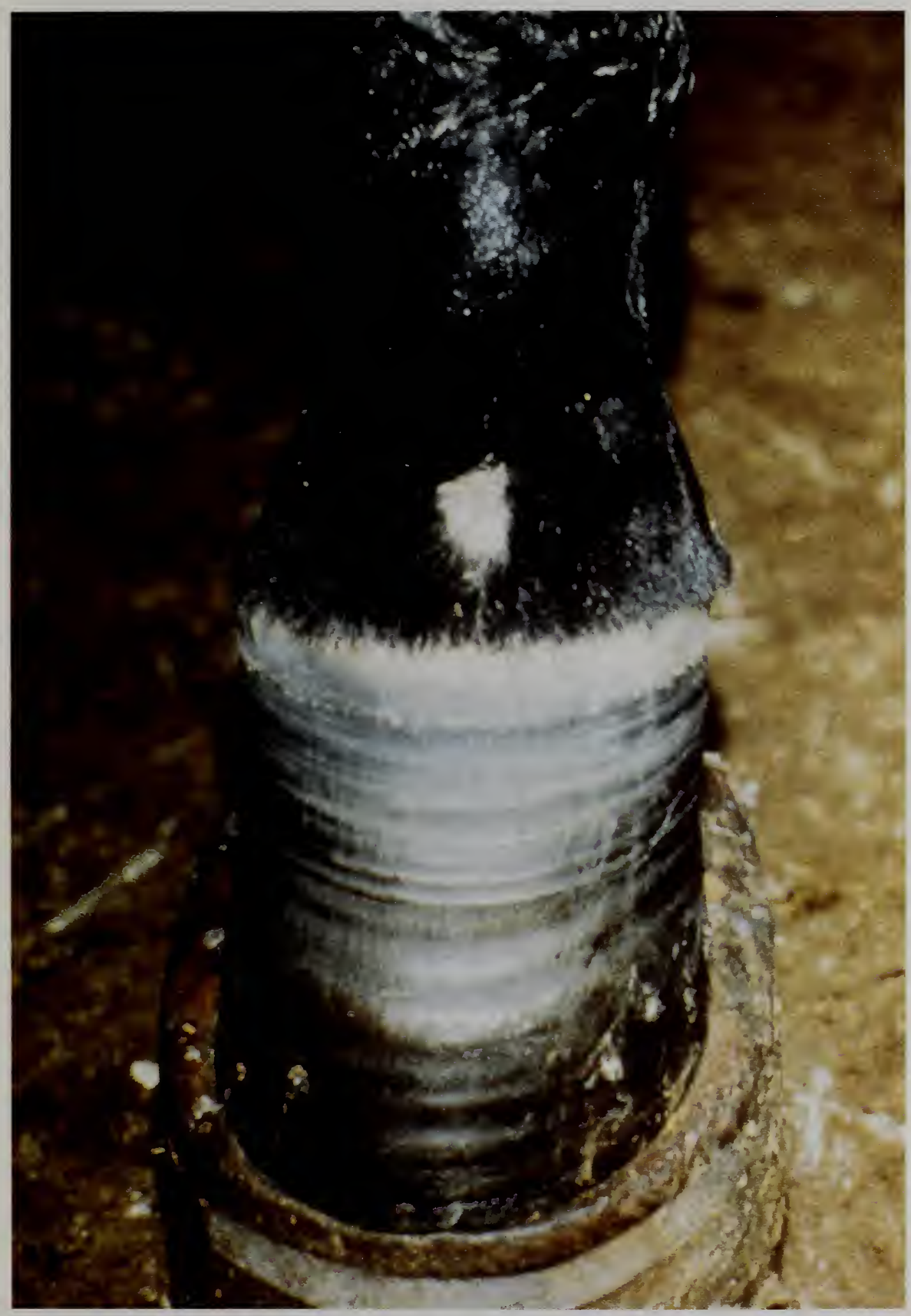

Figure 6-Violation. Scarring is present on the anterior surface (front) of a front leg pastern. 


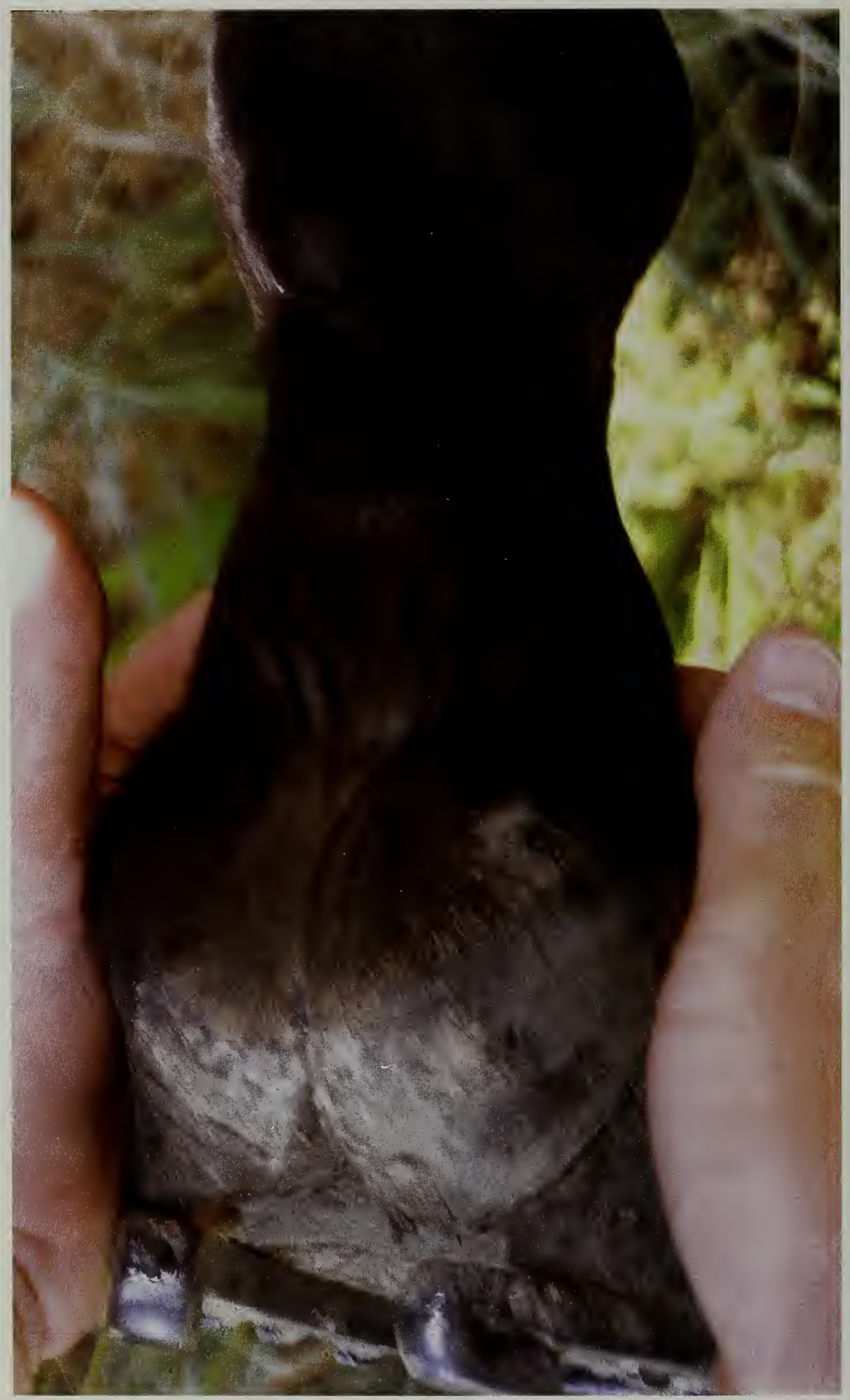

Figure 7-A small amount of folding of the skin exists on the back of the pastern. This may not be a violation if the skin can be determined to be uniformly thickened. (See fig. 8.) (APHIS photo by Clement Dussault.) 


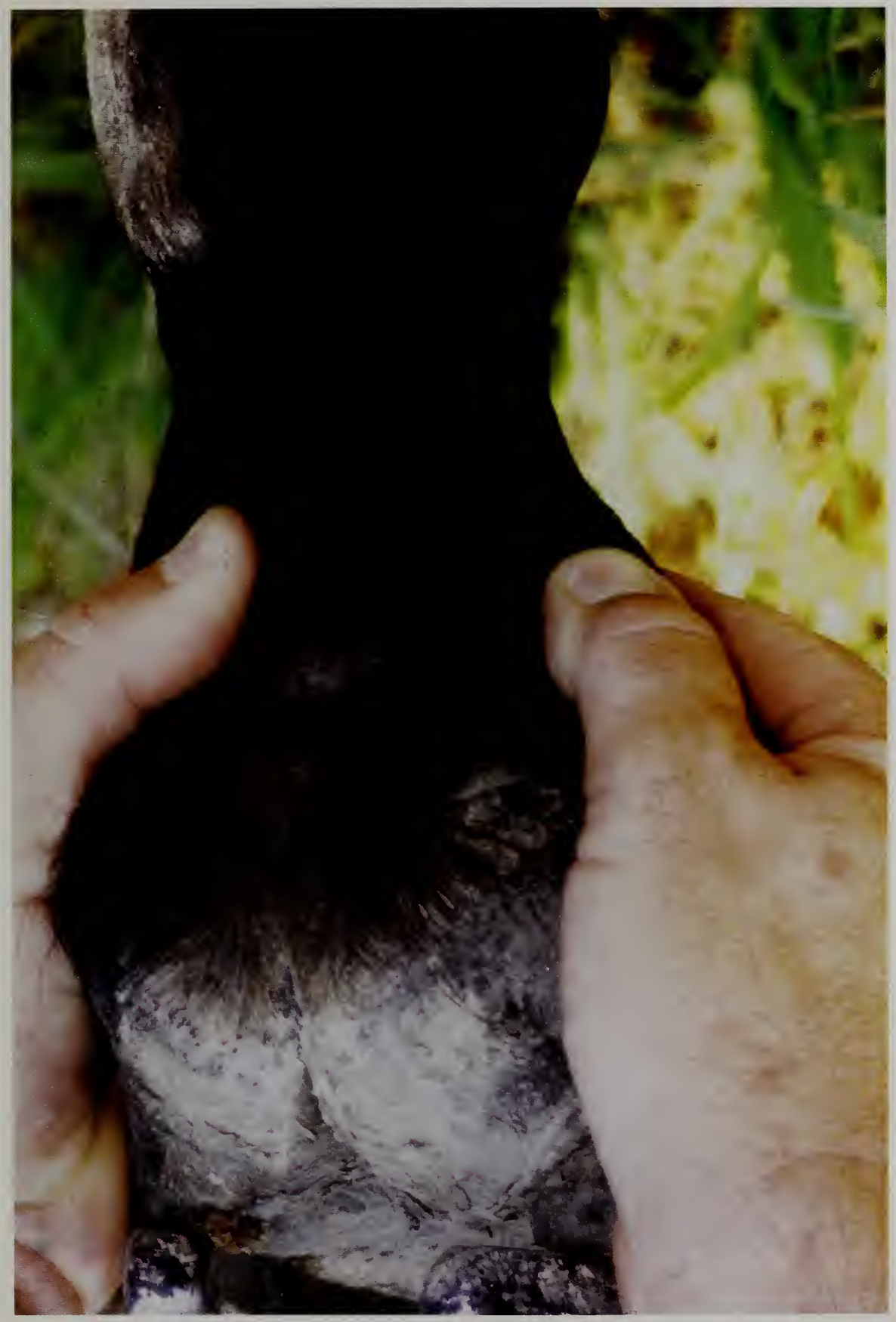

Figure 8-Spreading of the skin with the thumbs shows that the folds of skin can be smoothed out, indicating the skin is uniformly thickened. This is not a violation. (APHIS photo by Clement Dussault.) 


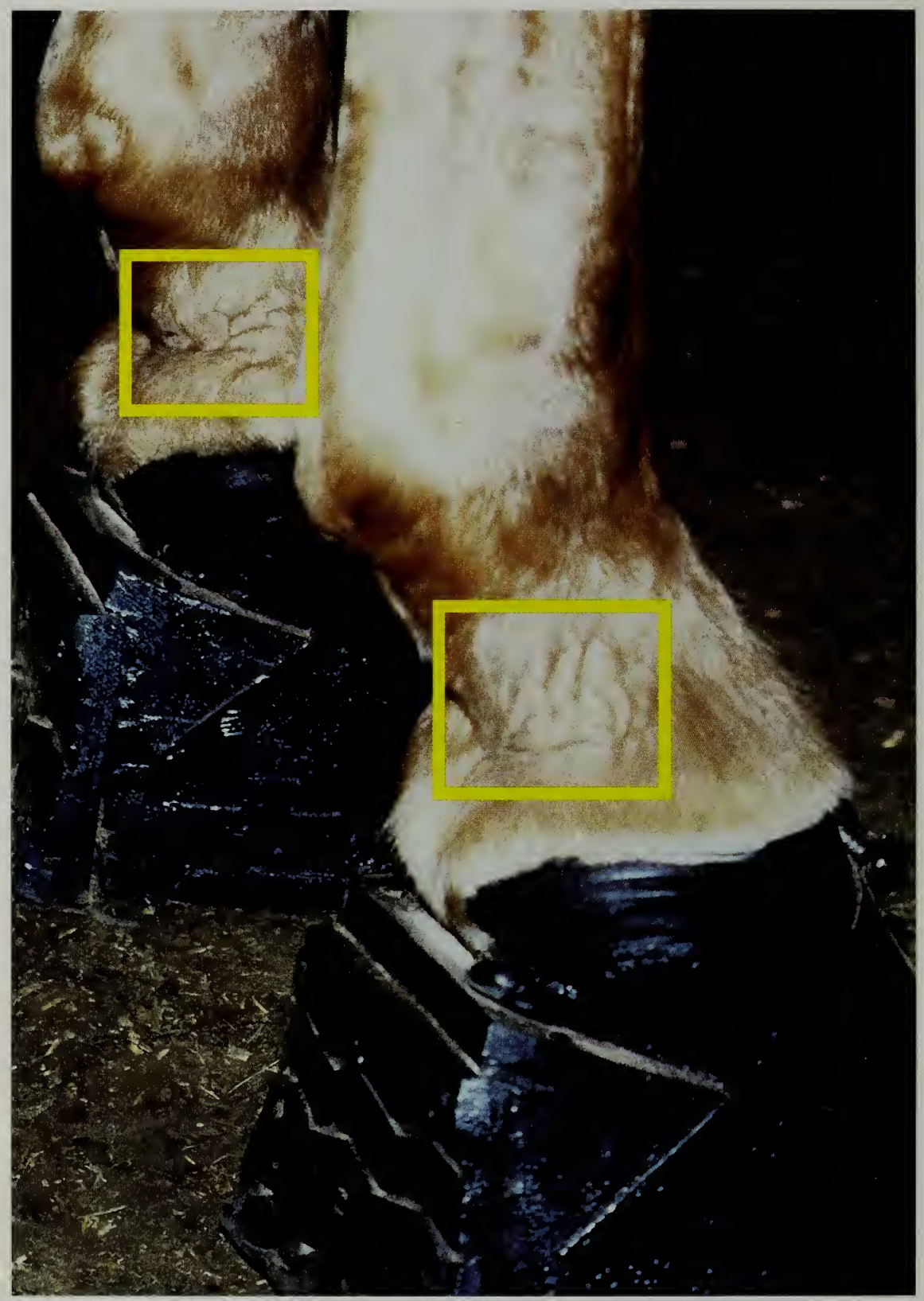

Figure 9-Violation. The scarring on the medial side (inside) of the left front pastern and on the lateral side (outside) of the right front pastern extends too far forward and beyond the limits of the posterior of the pastern. 


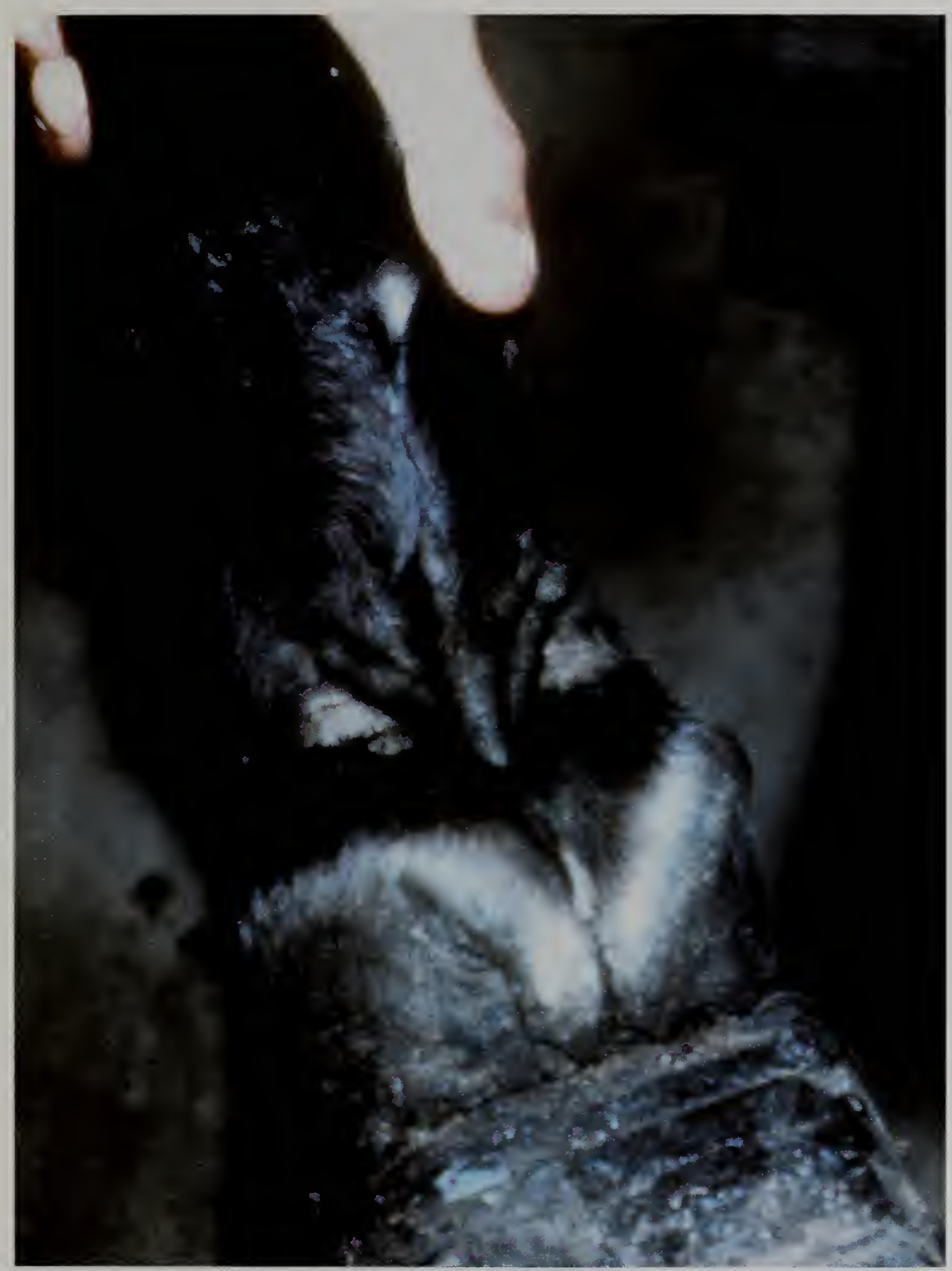

Figure 10-Violation. Nonuniformly thickened skin has ridges, deep furrows, and nodules. 


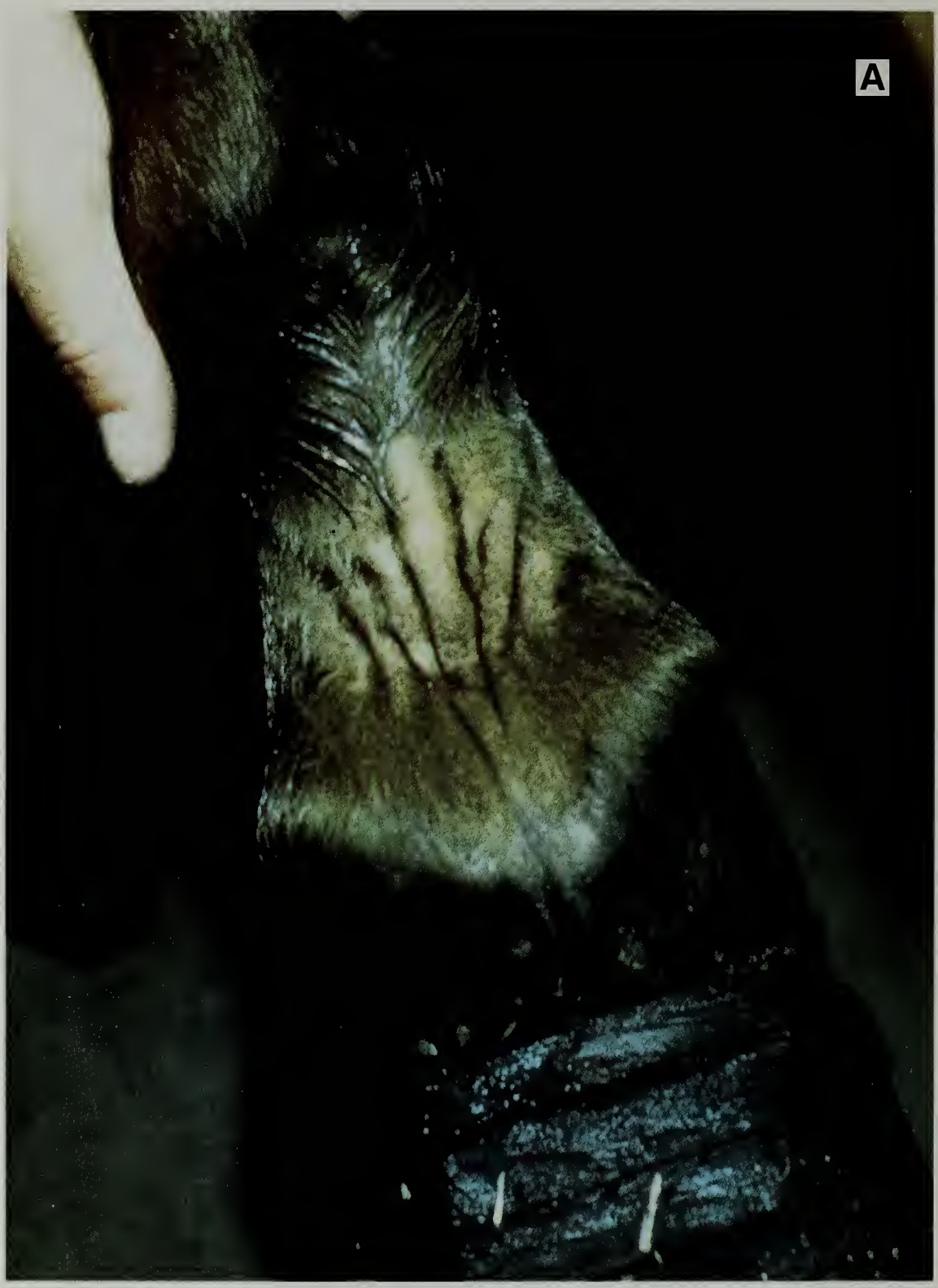

Figure 11A and B-The skin does not appear to be uniformly thickened. There are ridges and furrows present. If these can be smoothed out with the thumbs (see fig. 8), these would not be violations. (Photo B was taken by APHIS photographer Scott Price.) 


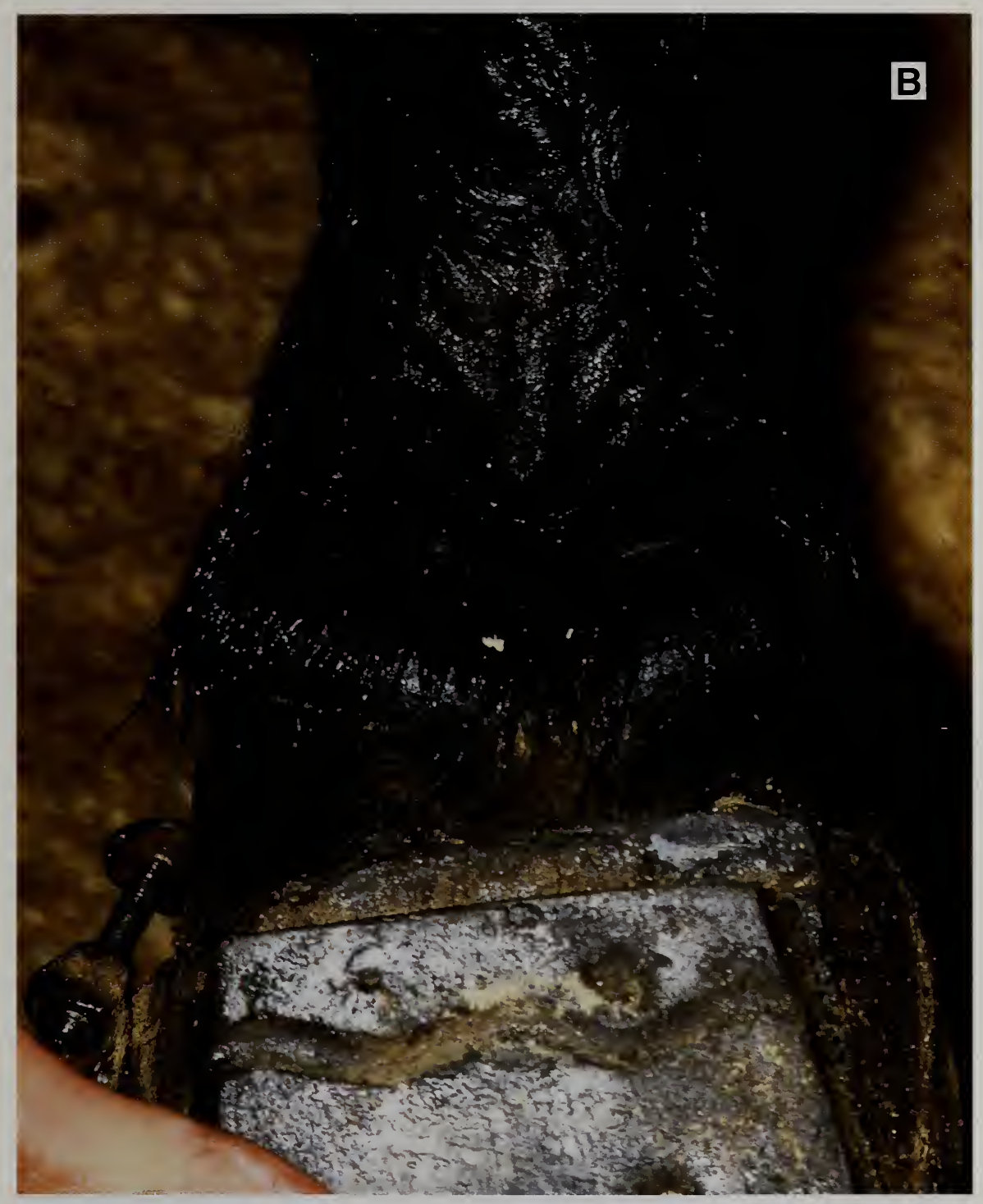




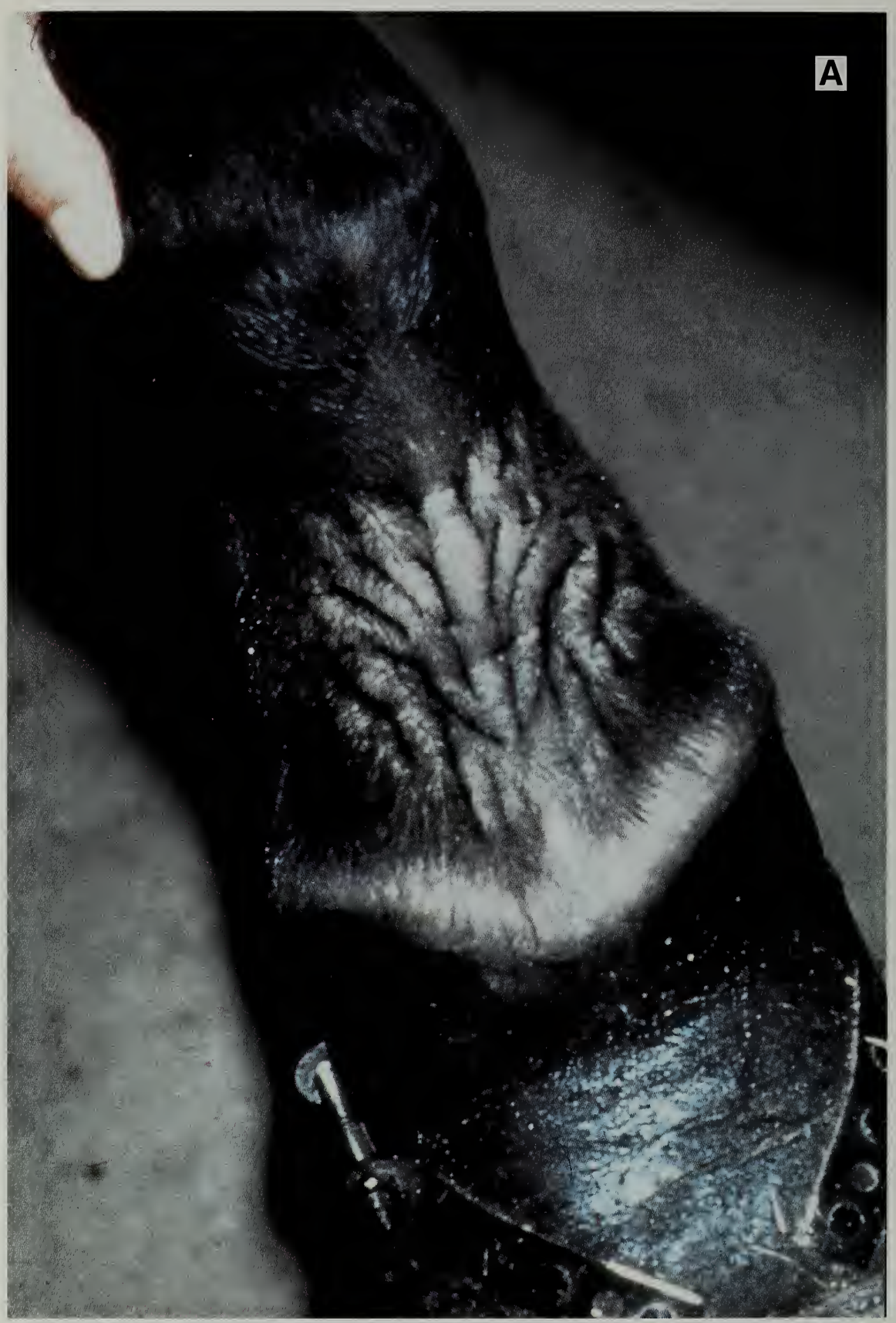

Figure 12A and B-The skin does not appear to be uniformly thickened. Ridges, corrugations, furrows, and some hair loss are present. These would be violations if the skin cannot be smoothed with the thumbs (see fig. 8). (Photo B was taken by APHIS photographer Scott Price.) 


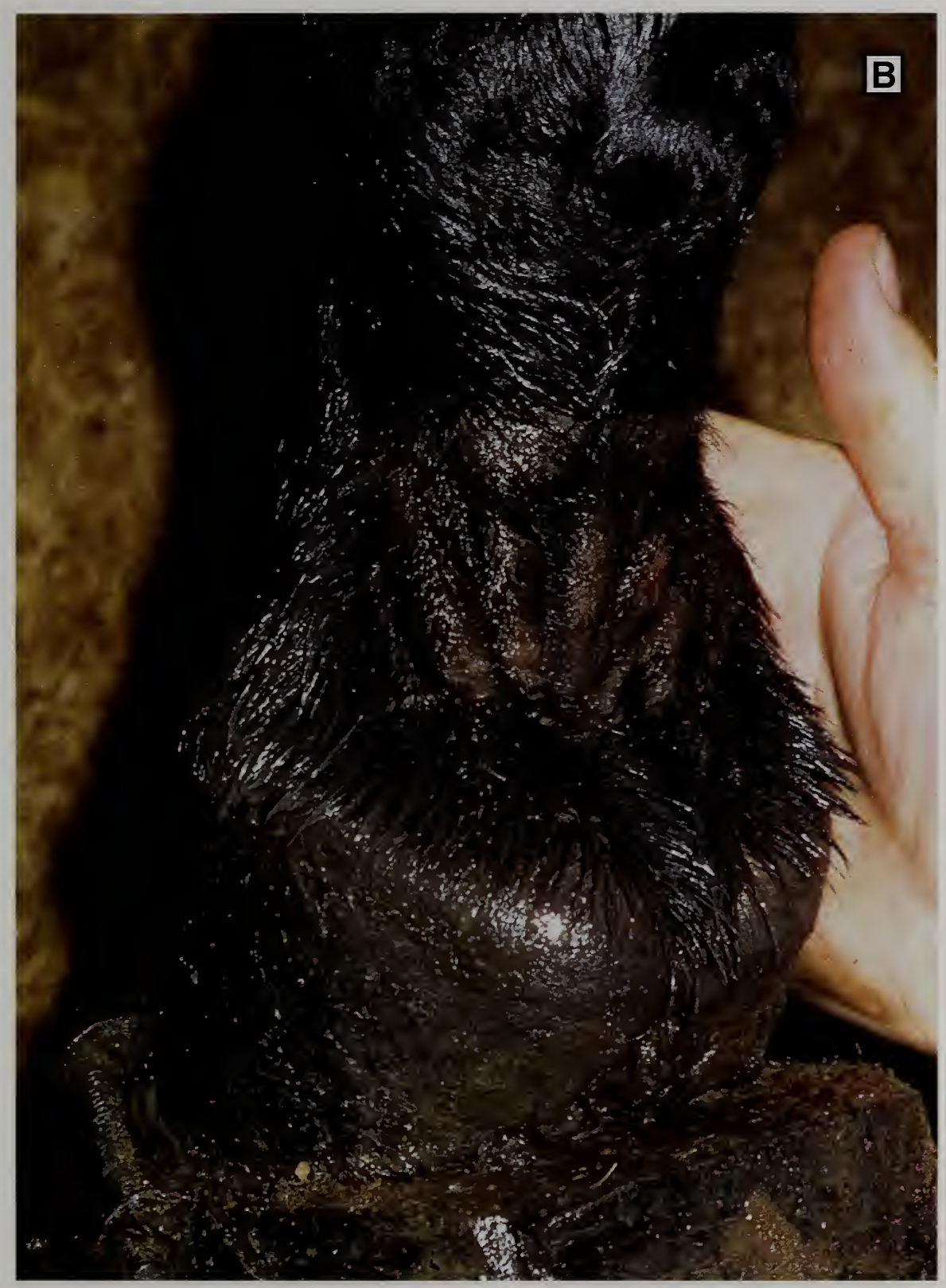




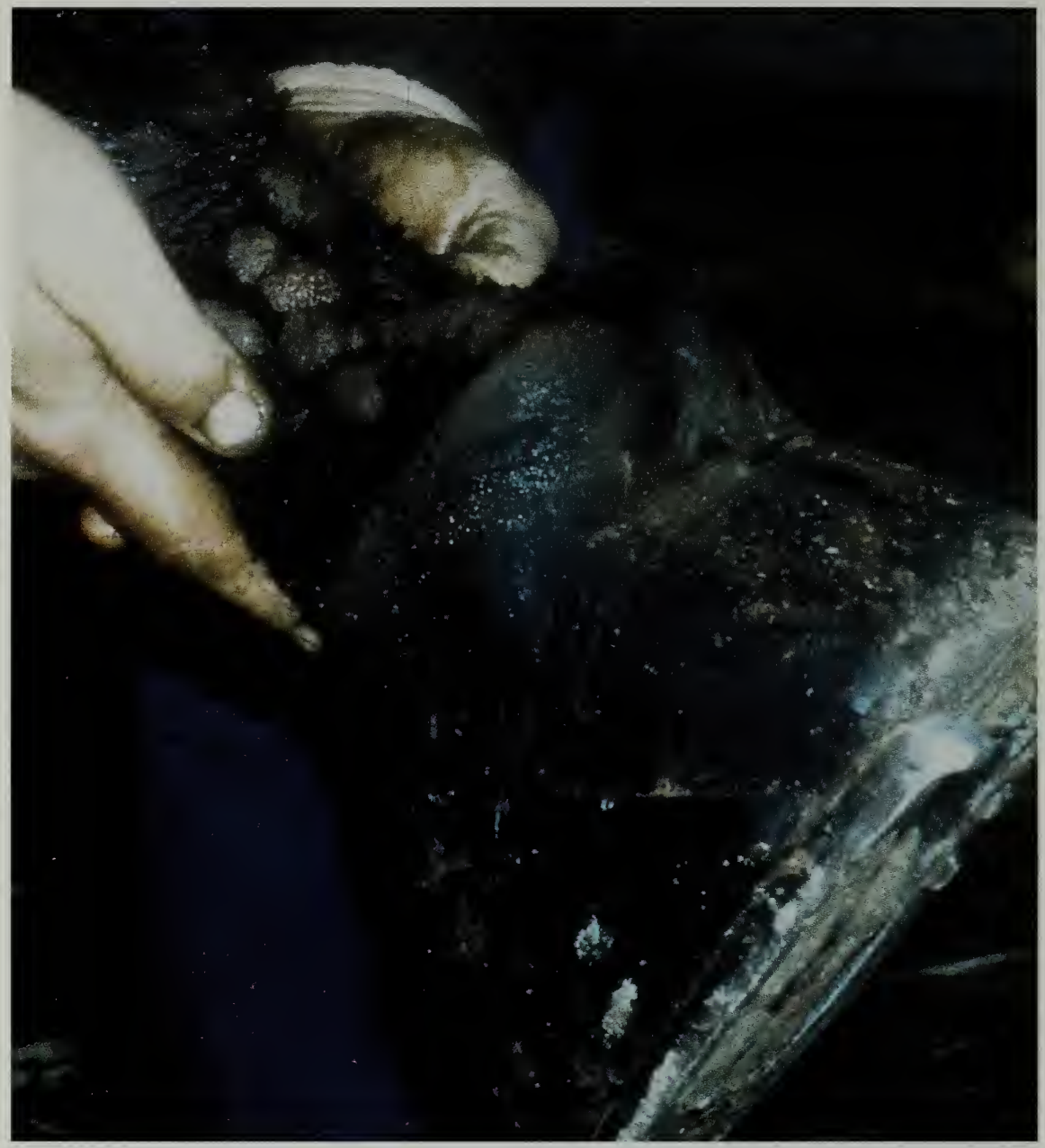

Figure 13-Violation. The skin is not uniformly thickened and shows signs of inflammation. There are a number of masses of scar tissue (button lesions) present. Note that the mass in the center appears to consist of reddened, inflamed granulation tissue. There is also a significant amount of hair loss. 


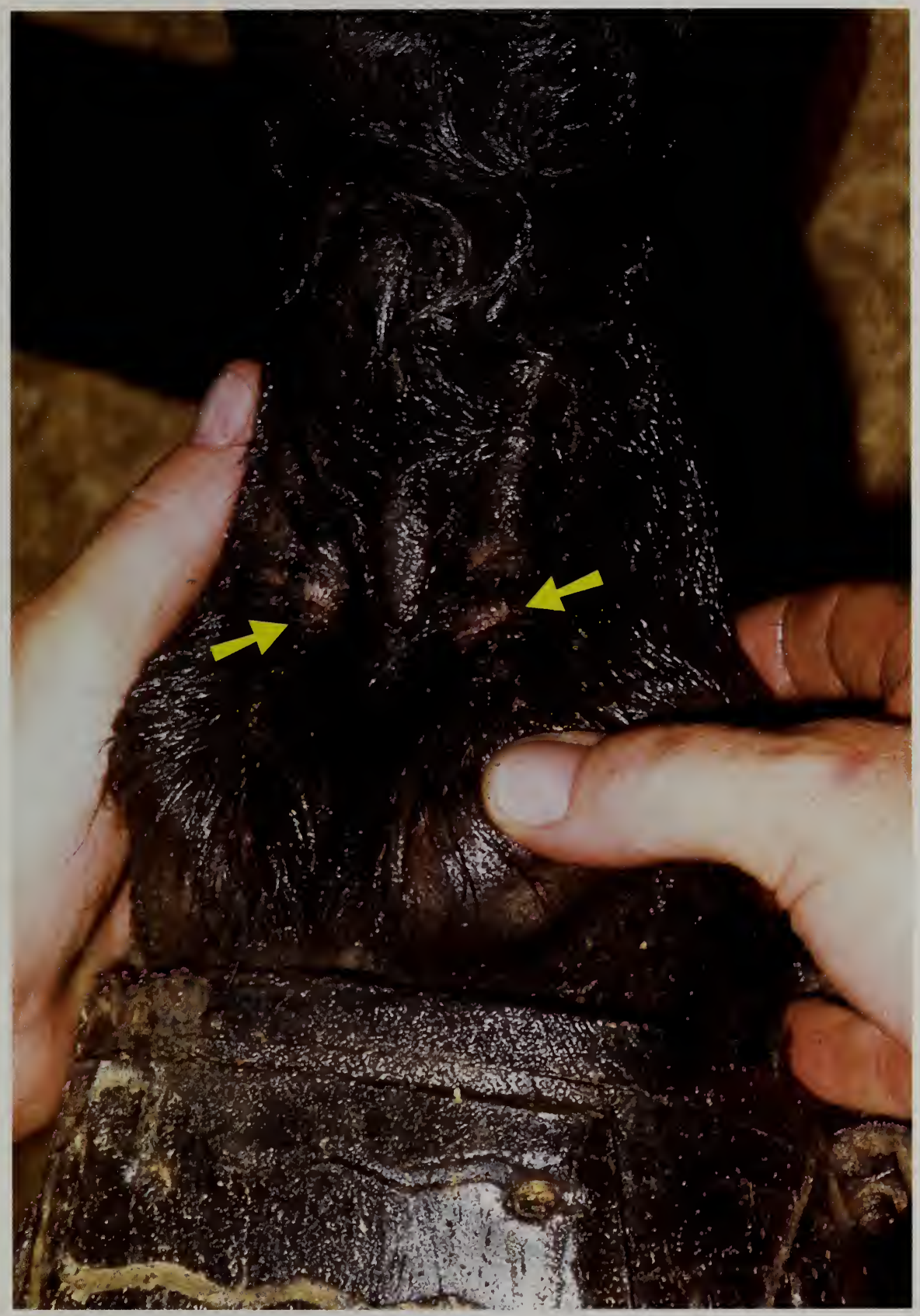

Figure 14-Violation. The skin is not uniformly thickened. It is folded into ridges and furrows with evidence of swelling and redness. The arrows point to red and swollen areas. (APHIS photo by Scott Price.) 


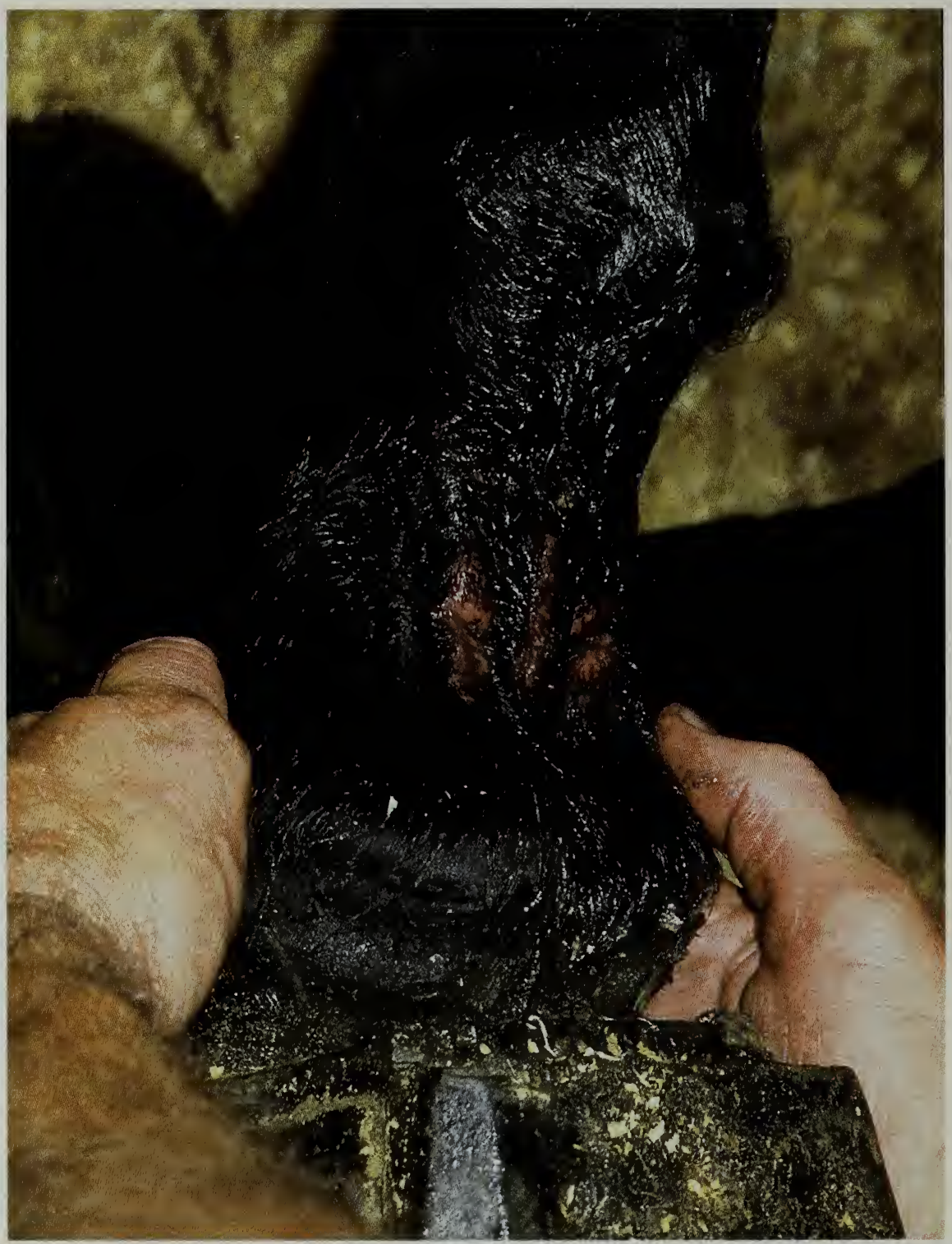

Figure 15-Violation. While the skin may be uniformly thickened, there are signs of inflammation, redness, and swelling present. (APHIS photo by Scott Price.) 
To be in compliance, the anterior surfaces of the horse's pasterns must be entirely free of scars indicative of soring. The posterior surface of the pastern must also be free of scars indicative of soring but is allowed to show uniformly thickened skin that is free of inflammation (i.e., showing no signs of redness, swelling, pain, or oozing).

It is important to keep in mind that, for there to be a scar rule violation, skin abnormalities must be found on both front pasterns. If the abnormalities are found on only one pastern, there is no violation. Though there must be abnormalities on both front pasterns, they do not need to be identical in appearance or location on the pastern for there to be a violation.

\section{Additional Information}

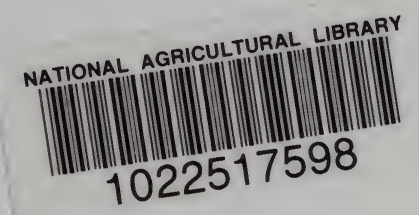

For more information about the HPA or the scar rule, or for answers to questions about information in this publication, please contact USDA or an HIO.

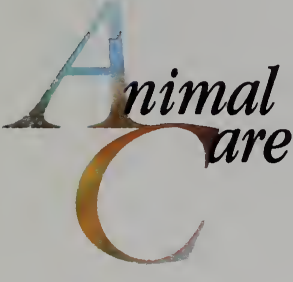

USDA, APHIS, Animal Care

4700 River Road, Unit 84

Riverdale, MD 20737-1234

Telephone: (301) 734-7833

Fax: (301) 734-4978

E-mail: ace@aphis.usda.gov

Web page: www.aphis.usda.gov/ac

Horse Industry Organizations:

- Heart of America Walking Horse Association

- Horse Protection Commission, Inc.

- Humane Instruction Technocracy, Inc.

- Kentucky Walking Horse Association-HIO

- Missouri Fox Trotting Horse Breed Association, Inc.

- National Horse Show Commission, Inc.

- National Walking Horse Association

- Spotted Saddle Horse Breeders and Exhibitors Association

- Western International Walking Horse Association 


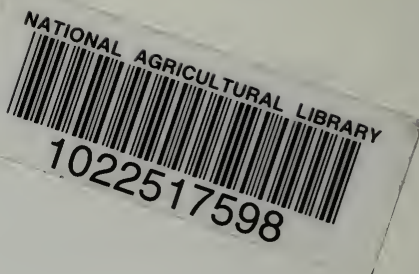

\section{$Z 0$ : $d h-y d Y 100 Z$}

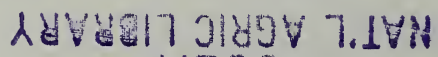
vasn 